\title{
SOURCES OF RISK AND MANAGEMENT STRATEGIES AMONG FOOD CROP FARMERS IN OSUN STATE, NIGERIA
}

Salimonu KK*1 and AO Falusi ${ }^{2}$

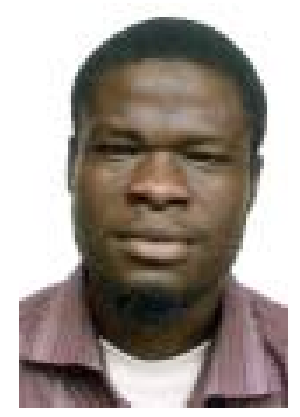

Salimonu Kabir

*Correspondence Author email: $\underline{\text { k_salimonu@ yahoo.com }}$

${ }^{1}$ Department of Agricultural Economics and Extension, Ladoke Akintola, University of Technology, P.M.B. 4000, Ogbomoso.

${ }^{2}$ Department of Agricultural Economics, University of Ibadan, Ibadan 


\section{ABSTRACT}

Food production decisions in Nigeria are made mainly by small-scale farmers who face a number of risks. In response, farmers engage in some risk management strategies which may have social and economic implications not only on the farming households in particular, but the entire economy. This study identified the sources of risk and the management strategies employed by the food crop farmers. A two-stage sampling procedure was used in the collection of primary data. The first stage involved a random selection of 30 farming communities from the three agroecological zones of the state's Agricultural Development Programme (ADP) namely Ife-Ijesa, Osogbo and Iwo zones. The second stage involved a random selection of food crop farmers from each of the villages with probability proportionate to size of each farming community. Data from 165 respondents were used for the analysis. Primary data collected included sources of risk, other environmental factors and management strategies employed. Secondary data were also obtained from Osun State Agricultural Development Programme (OSSADEP) records to complement the primary data. The data were analyzed using descriptive statistics and composite analysis. Sources of risk in the last three years were market failure, 54.5\%; price fluctuation, 46.1\%; drought, 32.7\%; pest and diseases attack, 33.9\% and erratic rainfall, 39.4\%. Majority of the food crop farmers in the study area were in the medium risk category. The mean value of 2.68 (approximately 3.0) implies that an average food crop farmer experienced up to three different sources of risk in the study area. Risk management strategies available to the farmers were extension services, $67.3 \%$; access to fertilizer, $41.2 \%$; mixed cropping/farming, $79.3 \%$; cooperative society $54.5 \%$, borrowing of money, $73.0 \%$ and off farm-work, $69.7 \%$. Attention should be shifted towards protection of farmers against market failure and price distortion or fluctuations as these, among others could impair the growth potential of these farmers. Investment in irrigation projects by the government would also save the farmers from drought and erratic rainfall while farmers are encouraged to benefit from the services of the agricultural insurance industry.

Key words: Risk, Food Crop, Management Strategies 


\section{INTRODUCTION}

Food production decisions in Nigeria are made mainly by small-scale farmers who face a number of risks. In response, farmers engage in some risk management strategies which may have social and economic implications not only on the farming households but the entire economy. This study identified the sources of risk and the management strategies employed by the food crop farmers. Definitive statements on effective strategies against failure in production and livelihood coping strategies during losses need to be seriously explored as these have great effects on the welfare of the farmers as well as food availability in the economy. The consideration of this is very important for effectiveness in increased food production programmes. Improvement in repayment of loans and aggregate commodity supply response, standard of living and employment of labour through investments are guaranteed if effective and efficient strategies are formulated against possible losses and failures in production.

Risk is an important aspect of the farming business. This is as a result of weather, yields, prices, government policies, global markets, and other factors that can cause wide swings in farm income [1]. It also refers to variabilities or outcomes, which are measurable in an empirical or quantitative manner [2]. These uncertainties are brought about as a result of three main causes: (i) environmental variations causing production and yield uncertainty (ii) price variation causing market uncertainty and (iii) lack of information [3]. All these are significant in African agriculture, where unreliable rains and pest and disease outbreaks cause wide variations in resource availability and in crop and livestock yields. Human diseases are frequent, unpredictable and costly to treat. Ill health or injury of a family member at a critical period may cause serious loss of production and income. Generally there are wide seasonal and unpredictable fluctuations in market prices, while information on alternative technologies or the market situation outside the immediate locality is often lacking. Hence the farmer cannot plan with certainty; his/her decisions are subject to risk. Much of the income of African smallholder farmers is highly vulnerable to drought. Lack of alternatives to rain-fed agriculture, technical non-viability of irrigation in many areas, widespread environmental degradation and poor access to commodity markets have together led to huge losses in income when droughts have struck. For example, maize production on Swazi communal farms fell dramatically from 145,000 metric tons in 1990-91 to 54,000 (less than half) metric tons in 1991-92 [4]; this further shows the huge losses associated with risk.

The study also seeks to explore the preventive and mitigation strategies as forms of risk management strategies. Information generated would be crucial in agricultural policies. The objectives of the study were: to examine the sources of risk in the last three years in the study area; and to identify risk management strategies employed by the farmers. 


\section{Importance of risk and uncertainties in agricultural production}

Land, labour (family and hired), fertilizer and credit have been identified as the major resources in farm production [5]. Efficient allocation of these resources in the face of risk inherent, therefore, becomes very important. Risk and uncertainties have played significant roles in agricultural production. It has been emphasized that uncertainties in yield and output prices are significant sources of farm-income variabilities [6]. In Osun State, aggregate crop production estimates were lower in 1994 than in 1993 due to lower hectarage put to different crops resulting from erratic rainfall and political crisis. This led to an unexpected higher cost of labour and other inputs [7]. The report further revealed attack of stem borer, which constituted an additional gross reduction in maize and rice yields. Okro and tomatoes also recorded reduced yield in 1995 due to heavy downpour of rainfall during flowering resulting in flower abortion. Inadequate and late supply of fertilizer to the state was the reason attributed to reduce maize yield in 1996 [7]. Agro-climatic variabilities have significant but varying effects in crop yield [8]. This gives a direction to farm eventualities classified as risks, which include the year-to-year variabilities in crop yield that are normally associated with fluctuations in weather and effects of other factors. A severe fall in the prices of cassava (49.12\%) in years 1999 and 2000 with reference to 1997 confirms these variabilities. Similar observations were recorded for white maize where the percentage fall in the prices in years 1998, 1999 and 2000 with reference to 1997 prices were $15.15 \%, 29.06 \%$ and $25.55 \%$, respectively [9].

Risks in agriculture are classified into property risks and personal risks according to the object or incidence of uncertainty. Risk to agricultural property may again be divided into natural, social and economic risks. Natural risks include storm, drought, lightening, flood, plant and animal diseases, hails and insect pests. Social risks involve fire, theft, embezzlement, industrial action, war, change in social structure and technology changes. The economic risks include fluctuations in prices of agricultural products, unexpected depreciation of assets and adverse terms of trade. Personal risks mean the probability of capital or income loss to the farmer arising from human factor [10]. Risk is further classified based on five major sources [11]. These are production, marketing, finance, legal and environmental/ human sources. However, three broad areas identified have been identified where risk has registered its effects in agricultural production. These are:

1) Individual (Idiosyncratic) - These include illness, loss of land or income earning opportunity and accident.

2) Community (local covariate) - which include flood, pest/ diseases, fire and communal clashes.

3) National (National covariate) - which include market failure, price changes, weather problem - rainfall and policy changes [12].

Poor rural households are particularly vulnerable to risk. Their risk management strategies tend to trap them in low risk but low return activities. Risk can be idiosyncratic or individual, in that it affects only one household in a community ( the disability of the primary income earner in a household) or it can be covariate or

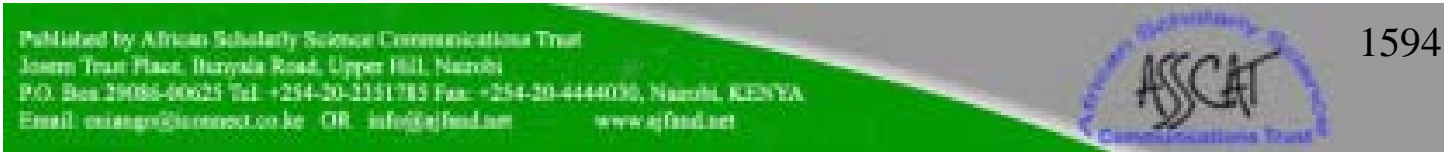


community-wide in that it simultaneously affects many or all households in a community (AIDS, drought, pest infestation, or war). Some risks can be repeated, such as recurring droughts or annual short-falls in food stocks of poor households in rural Africa prior to harvests. Others are singular events, such as old age. The more severe, prolonged or repeated the shocks are and the fewer the assets owned by the household, the less the household can protect its consumption level or avoid divesting itself of its assets to counter the drop in its income [13].

\section{Risk management strategies}

Risk management can then be defined as choosing among alternatives to reduce the effects of risk [14]. Farmers with access to risk management information and the knowledge to use it have the key to profitable and competitive farm operations. The problem is that small farmers, women, and limited resource producers often struggle to find and use appropriate information. This requires an evaluation of trade-off between changes in risk, expected returns and entrepreneurial freedom among others. The farmers tend to respond to changing farm risk in three broad stages: First, by insurance mechanisms as changes in cropping pattern and planting practices, reduced consumption and inter-household transfers. Second, by disposal of productive assets such as sales of livestock, agricultural tools, mortgaging of land or obtaining credit. The last stage includes starvation and migration [15]. The decision of reducing farm risks is usually made at the household level. In addition, spatial variations affect the responses to farm risk. Decisions on reducing farm risk are very much dependent on the geographic and socio-economic possibilities. Farmers living close to the market in the main city have better access to off-farm incomes than farmers living in more remote areas.

Three broad areas in risk management activities and measures by which they could be achieved are prevention, mitigation and coping [12].

1) Prevention: Training, Education, Extension services, Irrigation, Fertilizer provisions;

2) Mitigation: Crop Insurance, Crop diversification, Mixed farming, storage programme, Price support and cooperatives;

3) Coping: Hedging, Reduced consumption, Children out of school, Borrowing, selling of assets, selling of labour and off farm work.

\section{RESEARCH METHODOLOGY}

The study was carried out in Osun State, Nigeria. The State was chosen because of its location in the rainforest region and the availability of food crop farmers. Also, studies on food crop farmers in the study area especially as regards issues focusing on risk in agricultural production are scarce in the literature; an attempt to fill this void provides a basis for Osun State as the study area. A two-stage sampling procedure was used in the collection of primary data in Osun State. The first stage involved a random selection of 30 farming communities from the three agro-ecological zones of the state's Agricultural Development Programme. The second stage involved a random 
selection of food crop farmers from each of the communities with probability proportionate to size of each farming communities. Data from 165 respondents were used for the analysis. Using structured questionnaires, data used included environmental factors, risk sources (natural, social or economic) and the management strategies employed. Based on the literature, farmers were made to respond to some closed-ended options on questions relating to sources of risk in their respective areas. However, secondary data were also sourced from the Agricultural Development Programme (ADP) to complement the primary data. Analytical tools were mainly descriptive statistics with the incorporation of composite score method. The composite method was used to categorize the farmers based on their exposure to risk in the year 2004 farming season.

\section{RESULTS}

\section{Sources of risk}

The various sources of risk in the study area in the last three years $(2002,2003$ and 2004) were featured under three broad categories namely: natural, social and economic sources of risk as indicated by the farmers in the closed-ended questionnaire used in data collection. The corresponding percentage of farming households affected is also shown (Table 1). Results of the study are presented below:

\section{Natural risk sources}

These are flood, pest and diseases, erratic rainfall and drought. In 2002, 33.9 percent of the sampled food crop farmers had their farming activities affected by pests and diseases while 29.7 percent and 24.2 percent of them were affected in years 2003 and 2004, respectively. The incidence of erratic rainfall was 32.7 percent in year 2002, 37.0 percent in year 2003 and was highest (39.4 percent) in year 2004. The results of the study also show that 28.48 percent of the farmers had their farming activities affected by drought (2002), 32.7 percent (2003) and 30.3 percent (2004). Therefore, the occurrence of drought was highest in 2003 (32.7 percent).

\section{Social risk sources}

These are fire outbreak, change in government policy or social structure, illness of the farmer or any other member of the household, loss of land/ethnic clash or war and theft. The study reveals that risk due to fire outbreak was highest ( 9.7 percent) in year 2002 while the risk due to same were 7.9 percent and 3.0 percent for years 2003 and 2004, respectively. Risk sources due to change in government policy or social structure were fairly very low in the three years, considered in the study. While 3.6 percent of the farmers in the study area had their farming activities affected by this source of risk in 2002, about 4.8 percent and 3.0 percent were affected in years 2003 and 2004, respectively. The results also show that 4.2 percent of the farmers had their farming activities affected by illness of either the household head (the farmer himself) or other members, of the household in 2002. In years 2003 and 2004, the percentages were 6.1 percent and 3.0 percent, respectively. The analysis shows that in years 2002 and 2003, only 1.2 percent each of the farmers had their farming activities affected by

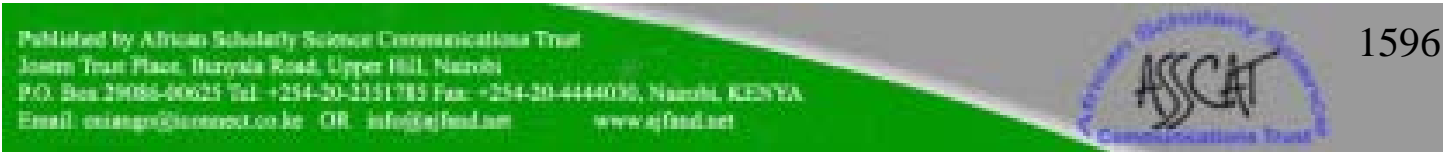


communal clashes. There was no such case recorded in year 2004. In 2002, 13.9 percent of the farmers experienced theft of their agricultural produce, 12.1 percent in 2003 and 15.1 percent in year 2004.

\section{Economic risk sources}

The results show that 39.4 percent of the farmers experience risk sources due to price fluctuations in year 2002, 46.7 percent in 2003 and 21.2 percent in 2004; hence the experience was highest in 2003 . The analysis shows that 48.5 percent of the farmers in the study area experienced losses due to market failure for their agricultural produce in 2002. In 2003, 54.5 percent had this problem while 20.0 percent of the farmers had the problem in 2004; hence, the highest occurrence was in year 2003.

\section{Categories of farmers based on their exposure to risk sources}

The distribution of farmer-respondents into three levels of risk categories based on the sources of risk they were exposed to in 2004 farming season is shown in Table 2. This is achieved using a composite score obtained from eleven different sources of risk as shown in Table 1. A respondent can score a maximum of 11 points if he or she is exposed to all the sources or a minimum of 0 point if he or she is not exposed to any of the sources. The mean score is 2.68 and the standard deviation is 1.22. The responses were then categorized into three. These are upper, medium and lower categories [16].

Upper Category $=($ Mean + Standard Deviation $)$ to $11=3.9$ to 11

Medium Category $=$ Between Lower to Upper Category Limit $=1.47$ to 3.8

Lower Category $=0$ to $($ Mean - Standard Deviation $)=0$ to 1.46

The table reveals that modal response was the medium risk (66.7 percent), followed by high risk (19.4 percent) and then low risk (13.9 percent) categories.

\section{Risk management strategies employed by the households Preventive strategies}

Table 3 shows the summary of preventive strategies against risk in the study area. Among the farmers, 23.0 percent had access to training and education from local government councils and non-governmental organizations, while 67.3 percent benefited from extension services. Extension service becomes a preventive strategy in that farmers do not only have access to relevant information but the capacity is also built thus they could operate outside the risk frontier. About 41 percent had access to the subsidized fertilizers sold by the government. Only 3.0 percent of the farmers were able to tackle drought through irrigation though over small area of land.

\section{Mitigation strategies}

Table 4 shows that mixed farming/cropping (79.3 percent) and Esusu- a revolving contributed cash (44.5 percent) were the two major mitigation strategies employed among the farmers. However, a few of the respondents (18.2 percent) had cribs and chemical use knowledge while 10.0 percent were mitigating using cooperative societies. Only 1.2 percent insured their cropping activities while none of them enjoyed price support programme. 


\section{Coping strategies}

During losses, Table 5 shows the coping strategies employed by the households. Two strategies were prominent. They were borrowing (73.0 percent) and off- farm work (69.0 percent). While 24.8 percent had to reduce their consumption, 24.2 percent sold their asset and 1.2 percent reposed their faith in God. None of them had their children out of school as a means of coping.

\section{DISCUSSION}

\section{Sources of risk:}

\section{Natural risk sources}

These are flood, pest and diseases, erratic rainfall and drought. It is shown from the table that for the three years under consideration, there was a general low occurrence of flood and/or storm in the study area. However, the highest occurrence was in year 2002 where 4.2 percent of the farmers claimed to have suffered the incidence. The study also shows that year 2002 witnessed greatest loss due to pest and diseases in the years under review in the study area. The farmers also recorded highest incidence of erratic rainfall in the year 2004. The occurrence of drought was highest in 2003 (32.7 percent). These implied that the farmers are exposed to natural risks in all the three years under consideration.

\section{Social risk sources}

These are fire outbreak, change in government policy or social structure, illness of the farmer or any other member of the household, loss of land/ethnic clash or war and theft. Risk sources due to change in government policy or social structure was very low in the three years considered in the study. This has implications in the channeling and availability of inputs such as fertilizer and credit facilities in most cases. The highest occurrence of this risk was in year 2003. The case of illness was also considered as a risk source. Illness of the farmer could delay when an activity is carried out. This is because the attention of the household would be shifted away from farming and paid to the sick person. This was also mostly experienced in year 2003 in the study area. Loss of land, ethnic or communal clash or wars as risk sources were generally low in the study area. Ethnic clash or war could threaten the existence of farming households in an area. Farmers may have to abandon their on-going farming activities, thereby resulting in a severe loss for the farmer. The occurrence of this source of risk was insignificant. In fact there was no such case recorded in year 2004. However, the case of theft recorded highest occurrence in year 2004. The problem of theft could be significantly controlled if the social capital affiliations in the area are strengthened.

\section{Economic risk sources}

These are market failure and price fluctuations. A price fluctuation means variability in the prices overtime. Market failure referred to a situation where the price of food crops has reduced drastically. It could also be referred to as the terminal end of price fluctuation. The results show that 46.7 percent of the farmers experience risk sources

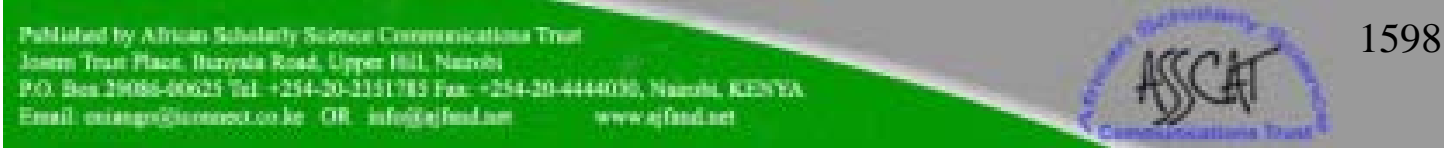


due to price fluctuations in year 2003 being the highest; hence the experience was highest in 2003. Risk sources due to market failure also constituted a source in the study area. The highest occurrence was in year 2003. Market failure is a problem which results when the farmers are not able to dispose their products, especially at the time when finances are required for household use. This happened especially for cassava in years 2002 and 2003 [17]. The demand for this crop fell drastically; losses were, therefore, experienced through severe low price for the product.

Table (1) further shows that five sources constituted the major sources of risk in each of the three years under consideration. A close look at the Table shows that the incidence of three out of these five sources was highest in the year 2003. These are market failure (54.5 percent), price fluctuation (46.7 percent) and drought (32.9 percent). However, pest and diseases attack was highest in the year 2002 (33.9 percent) while erratic rainfall (39.4 percent) was highest in 2004. On the whole, risk source due to loss of land was the lowest in the years under consideration. The record of the ADP also showed that diseases like downy mildew of maize, army worm infestation, nematode disease of yam and African cassava mosaic were experienced in the study area. Others are bush fire outbreak and flood disaster. These however, had effects like reduction in farmers' productivity, reduction in farmers' income and food shortage [7].

\section{Categories of farmers based on their exposure to risk sources}

Table 2 reveals that modal response was the medium risk ( 66.7 percent) followed by high risk (19.4 percent) and then low risk (13.9 percent) categories. This implies that majority of the food crop farmers in the study area were in the medium risk category. The mean value of 2.68 (approximately 3.0) implies that an average food crop farmer experienced up to three different sources of risk in the study area.

\section{Risk management strategies employed by the households}

The risk management strategies available and employed by the farmers were featured under three categories: preventive, mitigation and coping. More than half of the farmers still had access to extension services as a form of preventive measures. The reasons for this could be featured from two different view points. First, this is contrary to similar studies that farmers do not have up-to-average extension service delivery [18]. Second, even if the assertions from earlier studies are true that the farmers do not have enough opportunities for extension services, then the result of this current study may be a revelation of the adjustments in the policies of the Federal Government about the extension programme stemming from the specific policy recommendations from earlier studies. The mitigation strategies are expected to reduce risk incidence. This has been somewhat achieved in the study area through mixed farming/cropping and cash contributions. This is in consonance with a study on 'effects of organic and mineral fertilizers on growth and yield of pepper' [19] where majority of the farmers were found operating mixed farming / cropping. However, the risk mitigation strategies through price support programme were still very low in the study area. The coping strategies mostly employed were borrowing (73.0 percent) and off- farm work (69.0 percent). The farmers were coping by borrowing money for the next farming

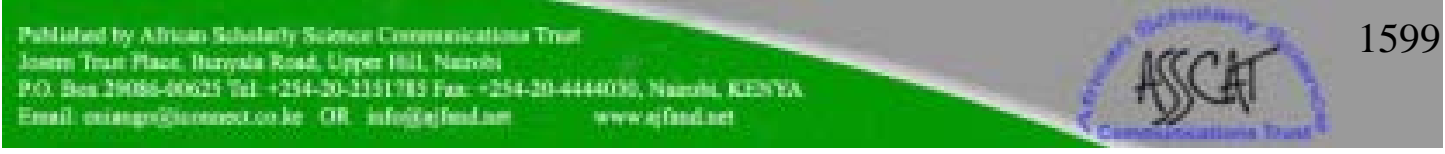


operation, food consumption, or other domestic uses. The off-farm works among others include basket weaving and felling trees for sale.

\section{CONCLUSIONS, POLICY IMPLICATIONS AND RECOMMENDATIONS}

Five major risk sources were prominent in the last three years. These were market failure, price fluctuation, erratic rainfall, drought and pest and diseases attack. However, loss due to land losses was the lowest. With regard to exposure to different sources of risks, most farmers belong to medium risk category where an average farmer was exposed to up to three sources of risk. While 23.0 percent had access to training and education from local government councils and non-governmental organizations; 67.0 percent benefited from extension services as part of the preventive mechanisms toward risk. The most employed mitigation strategies were mixed cropping (79.3 percent) and Esusu- revolving contributed cash (44.5 percent). The study shows that borrowing of money (73 percent) and off- farm work ( 69.70 percent) were the most prominent as coping strategies. The risk sources which were faced by farmers in the study area would continue to threaten the survival of farmers' households in particular and shortages in food production in the economy in general. The environment, therefore, needs policy interventions that can bring together the major stakeholders in food production programme. These include the farmers themselves, researchers, extension agents and the government. Thoughts should be raised towards varieties of planting materials - seeds and cuttings - that are drought tolerant and pest and diseases resistant. Price support programme towards the protection of farmers against price distortion or fluctuations should be put in place as these problems among others could impair the growth potentials of these farmers. Investment in irrigation projects by the government would also save the farmers from drought and erratic rainfall while farmers are encouraged to benefit themselves from the services of the agricultural insurance industry. 
Table 1: Sources of risk

\begin{tabular}{|c|c|c|c|}
\hline Sources & 2002 & 2003 & 2004 \\
\hline & $\begin{array}{l}\text { Percentage of } \\
\text { households }\end{array}$ & $\begin{array}{l}\text { Percentage of } \\
\text { households }\end{array}$ & $\begin{array}{c}\text { Percentage of } \\
\text { households }\end{array}$ \\
\hline \multicolumn{4}{|l|}{ a._Natural risk } \\
\hline Flood/storm & 4.24 & 1.21 & 1.21 \\
\hline Pest and Diseases & 33.94 & 29.70 & 24.24 \\
\hline Erratic rainfall $^{1}$ & 32.72 & 36.97 & 39.39 \\
\hline Drought $^{2}$ & 28.48 & 32.72 & 30.30 \\
\hline \multicolumn{4}{|l|}{ b. Social risk } \\
\hline Fire outbreak & 9.69 & 7.89 & 3.03 \\
\hline $\begin{array}{l}\text { Change in government } \\
\text { policy/social structure }\end{array}$ & 3.64 & 4.84 & 3.03 \\
\hline Illness of household member & 4.24 & 6.06 & 3.03 \\
\hline Loss of land/Ethnic clash/war & 1.21 & 1.21 & 0.00 \\
\hline Theft & 13.94 & 12.12 & 15.15 \\
\hline \multicolumn{4}{|l|}{ c. Economic risk } \\
\hline Market failure & 48.48 & 54.54 & 19.99 \\
\hline Price fluctuation & 39.40 & 46.66 & 21.21 \\
\hline
\end{tabular}

Table 2: Risk sources categories among the farmers

\begin{tabular}{lll}
\hline Risk categories & Frequency & Percentage \\
\hline High Risk Category & 32 & 19.40 \\
Medium Risk Category & 110 & 66.70 \\
Low Risk Category & 23 & 13.90 \\
Total & $\mathbf{1 6 5}$ & $\mathbf{1 0 0}$ \\
\hline
\end{tabular}

${ }^{1}$ Refers to inconsistency, unpredictable and "changing direction" rainfall pattern

${ }^{2}$ Refers to a long period of extremely dry weather when there is no enough rain for the successful growing of crops 
Table 3: Preventive strategies

\begin{tabular}{ll}
\hline Preventive strategies & Percentage* $^{*}$ \\
\hline Extension Services & 67.27 \\
Fertilizer Provision & 41.21 \\
Training and Education & 23.03 \\
Irrigation & 3.03 \\
\hline
\end{tabular}

* Percentages of household preventive strategies are multiple responses

Table 4: Mitigation strategies

\begin{tabular}{ll}
\hline Mitigation strategies & Percentage $^{*}$ \\
\hline Mixed Cropping/Farming & 79.39 \\
Esusu (cash contribution) & 44.50 \\
Cooperative Societies & 10.04 \\
Storage Programme & 18.18 \\
Crop Insurance & 1.21 \\
Price Support & 0.00 \\
\hline
\end{tabular}

* Percentages of household mitigation strategies are multiple responses 
Table 5: Coping strategies

\begin{tabular}{ll}
\hline Coping strategies & Percentage* \\
\hline Borrowing & 73.33 \\
Off Farm Work & 69.70 \\
Reduced Consumption & 24.85 \\
Selling of Assets & 24.24 \\
Faith in God & 1.21 \\
Children Out of School & 0.00 \\
\hline
\end{tabular}

* Percentages of household coping strategies are multiple responses 


\section{REFERENCES}

1. Dismukes $\mathbf{R}$ Farm risk management http//www.ers.usda.gov/Briefing/risk Management html.accessed 26/01/2006. 2005.

2. Olayide SO and EO Heady Introduction to agricultural production economics, Ibadan University Press Publishing House, University of Ibadan, Ibadan. 1982;135-139.

3. Upton M The economics of tropical farming systems. Cambridge University Press, 1996; 117pp.

4. World Bank Swaziland: reduction poverty through shared growth". Poverty policy study overview Report. Human Development Group1, Africa Region. Washington, D.C. 2000.

5. Amaza PS and JK Olayemi An investigation of production efficiency in food crop enterprises, Gombe state, Nigeria. J. of Rural Econs. and Developmentt, Vol. 13, No. 2. 1999; 111-122.

6. Isik M Resource management under production and output price uncertainty. implication for environmental policy. American J. of Agric. Econs. 84 (3), 2002; $557-591$.

7. OSSADEP. Osun state agricultural development programme, Annual Reports 1992-2001.

8. Akintola JO Forecasting food crop yields from meteorological variables. J.of Econs. and Social Development Vol. 14, No.1, 1999; 24-33.

9. OSSADEP. Crop area and yield survey. Conducted by Planning, Monitoring and Evaluation Department 1994-1996.

10. Ray PK Agricultural insurance: principles, organization and application to developing countries. $2^{\text {nd }}$ Edition, Pergamon Press, Oxford England, 1980.

11. Baquet A, Hambleton $\mathbf{R}$ and D Jose Introduction to risk management. In: Wesley, N.M., George, F.P. and Ullerich, S. 2002. Demonstrating differences in risk attitudes, J. of American Society of Farm Managers and Rural Appraisers (ASFMRA); www.asfmra.org. 1993.

12. Okunmadewa F Risk, vulnerability in agriculture: concept and context. A paper presented at staff seminar, Department of Agricultural Economics, University of Ibadan, 2003.

13. World Bank Dynamic risk management and the poor: developing a social protection strategy for Africa", Africa Region Human Development Series. Washington DC, USA. 2001 
14. Harwood J, Heifner R, Coble K, Perry T and A Somwaru Managing risk in farming: concepts, research and analysis. Agric. Econs. Report No. 774. Market and Trade Economic Division and Resource Economics Division, Economic Research Service U.S.Department of Agriculture. March, 1999.

15. Corbett J Famine and household coping strategies. In: World Development, vol. 16, No. 9, 1988;1099-1112

16. Yekinni OT Political Economy of Agricultural Policy Implementation in Nigeria: Oyo State an a case study. A Research Project Submitted to F. S. Idachaba Foundation for Research and Scholarship, Ibadan, 2007.

17. National Special Program for Food Security (NSPFS) Report on Comprehensive Marketing Study, Osun State, 2005.

18. Salimonu KK and OT Yekinni Determinants of Participation in Off-farm Income Activities among Food Crop Farmers in Akinyele Local Government Area of Oyo State, Nigeria; Book of proceedings Annual Conference NAAE $2006 ; 167-172$.

19. Adeola RG Effects of Organic and Mineral Fertilizers On growth and Yield of Pepper (Capsicum Annuum L.) Under Cassava (Manihot Esculenta Crantz) Relay Intercrop, in Ogbomoso, Nigeria. P.hD Thesis Department of Agronomy, University of Ibadan, Nigeria, 2007. 